\title{
Simultaneous detection of expression and gene mutations of HER2/neu in Chinese patients with gastric cancer
}

\author{
XIULI ZHANG ${ }^{1}$, JIANHUI QU ${ }^{2}$, GANG SUN $^{1}$, JING YANG ${ }^{1}$ and YUNSHENG YANG ${ }^{1}$ \\ ${ }^{1}$ Department of Gastroenterology and Hepatology, Chinese PLA General Hospital; \\ ${ }^{2}$ Infectious Department No. 9, 302 Hospital of Chinese PLA, Beijing, P.R. China
}

Received January 11, 2010; Accepted March 11, 2010

DOI: 10.3892/ol_00000099

\begin{abstract}
HER2/neu is one of the few identified oncogenes in tumorigenesis. Attention has been focused on the potential effect of HER2/neu mutations in the tyrosine kinase domain on carcinoma-targeted therapy. However, data concerning HER2/neu mutations in Chinese patients with gastric cancer (GC) are limited. This study aimed to detect the expression and somatic mutations of HER2/neu in Chinese patients with GC. Immunohistochemical staining for HER2/neu was performed on 72 formalin-fixed, paraffin-embedded specimens of GC (40 intestinal and 32 diffuse type). The correlation between the overexpression of HER2/neu and clinicopathological parameters was statistically analyzed. Somatic mutations in the tyrosine kinase domain of HER2/ neu in the 72 patients were detected by direct sequencing. In the GC group, overexpression of HER2/neu was detected in 13 of the 72 GC patients and in 4 of the 72 adjacent tissues in the non-tumorous group ( 18.1 vs. $5.6 \%, \mathrm{P}<0.05)$. Furthermore, the intestinal type of GC exhibited a higher rate of HER2/neu overexpression than the diffuse type ( 29.7 vs. $5.7 \%, \mathrm{P}<0.05)$. The rate of HER2/neu overexpression in stage III-IV (TNM stage) GC cases was significantly higher than that in stage I-II (28.2 vs. $6.6 \%, \mathrm{P}<0.05)$. HER $2 /$ neu overexpression correlated with a significantly less favorable patient survival $(\mathrm{P}=0.046)$. No somatic mutations in the tyrosine kinase domain of HER2/ neu were detected in tumor tissues or the corresponding nontumorous ones in the specimens obtained from the 72 Chinese GC patients. Results suggest that overexpression of HER2/ neu is a frequent molecular event strongly associated with a poor patient prognosis, whereas the incidence of somatic mutations of the HER2/neu kinase domain is more likely a low-frequency event in Chinese GC patients.
\end{abstract}

Correspondence to: $\mathrm{Dr}$ Yunsheng Yang, Department of Gastroenterology and Hepatology, Chinese PLA General Hospital, 28 Fuxing Road, Beijing 100853, P.R. China

E-mail: sunny301ddc@126.com

Key words: HER2/neu, gastric cancer, gene mutation, overexpression

\section{Introduction}

Numerous studies have focused on the pathogenesis of the HER [human epidermal growth factor receptor (EGFR)related] family in tumorigenesis. Moreover, HER-related signal pathways are proving to be promising, effective molecular targets for anti-tumor therapy including treatment for gastric cancer (GC) (1-4). The HER family consists of four closely related members: EGFR/HER1, HER2/neu, HER3 and HER4. HER receptors share a high degree of structural and functional homology, including a glycosylated extracellular ligand-binding domain, a hydrophobic transmembrane domain and an intracellular domain with tyrosine kinase activity (except HER3) $(5,6)$. The formation of homodimerization or heterodimerization induced by binding with neuregulins, $B$ cellulin and heparin-binding EGF-like growth factor triggers a complex signal transduction cascade, predominantly through phosphoinositide-3-kinase/Akt and extracellular signal-regulated kinase $1 / 2$, thereby regulating the proliferation, migration, adhesion, angiogenesis and apoptosis of cancer cells $(7,8)$.

The special importance of HER2/neu in tumorigenesis implies that signaling pathways and downstream effectors have evolved into key molecules in carcinoma-targeted therapy. Herceptin, for example, a humanized monoclonal antibody targeting the HER2/neu antigen, has been used as first-line cancer therapy in breast cancer patients when tumors overexpress HER2/neu (9,10). Therapy benefits in GC patients from the utility of herceptin were also reported in pre-clinical trials $(11,12)$.

Somatic mutations of the HER genes have drawn much attention in cancer research, particularly after the notable finding that EGFR gene mutations in non-small cell lung cancer predict clinical responses to EGFR tyrosine kinase inhibitors (13). The potential effect of HER mutations, including HER2/neu, has become an important event in the fields of cancer genetics and therapeutics (14).

According to published data, the incidence of HER2/neu mutations in cancer tissues is modest (2.9-5\%) (15). The gene mutation may vary depending on the ethnicity of the cancer patients. To the best of our knowledge, however, no reports on HER2/neu mutations in Chinese patients with GC exist. In the present study, the somatic mutations of HER2/neu and its expression in 72 Chinese patients with GC were investigated concomitantly. 


\section{Materials and methods}

Patients. Seventy-two patients diagnosed with GC and identified from the pathology archives of the General Hospital of PLA (from 2004 through 2006) were randomly enrolled in this study. Patients that underwent curative surgery had no prior treatment such as chemotherapy or radiation therapy. Of the 72 patients, 40 were men and 32 women with a mean age of 52 years (range 41-78). In each case, GC tissues and adjacent non-tumorous tissues (non-tumor group) were obtained for pathological examination. The detailed pathological results were obtained from the Department of Pathology of our hospital. The study protocol was approved by the Clinical Research Ethics Committee of the Chinese PLA General Hospital. Informed consent was obtained from each patient.

The histological tumor type of GC was defined according to Lauren's classification. In this study, the 72 patients with GC included 40 intestinal- and 32 diffuse-type. Tumor node metastasis (TNM) staging was performed at the pathologic diagnosis of GC according to the American Joint Committee on Cancer staging system (Table I). Patients were followed up for 8-30 months.

Microdissection. Tumor and normal cells from the same patients were selectively procured from hematoxylin and eosin-stained slides, using a 30G1/2 hypodermic needle (Becton Dickinson, Franklin Lakes, NJ, USA). The needle was affixed to a micromanipulator by microdissection. DNA extraction was performed by a modified single-step DNA extraction method and then overnight digestion with SDS and proteinase $\mathrm{K}$ at $37^{\circ} \mathrm{C}$. This procedure was followed by standard phenol-chloroform (1:1) extraction and ethanol precipitation.

Immunohistochemistry (IHC). Sections $(5 \mu \mathrm{m})$ of formalinfixed, paraffin-embedded tissues were dewaxed in xylene and rehydrated through a series of ethanol. Antigen retrieval was carried out at this stage in a microwave oven. Sections were then blocked with 3\% hydrogen peroxidase followed by incubation with a $50 \%$ protein blocking agent. Fetal bovine serum (10\%), with or without the HER2/neu antibody (1/100), was applied to each slide and incubated for $30 \mathrm{~min}$. Slides were counterstained with hematoxylin and mounted. Omission of the specific antibody was used as the negative control. The anti-HER2 monoclonal antibody (Dako Herceptin Test kit) and Dako EnVision ${ }^{\mathrm{TM}}$ kit (DakoCytomation Co., Denmark) were used for the IHC staining.

After the IHC staining, slides were microscopically interpreted in a blinded fashion by two pathologists. Membrane staining for HER2/neu was taken into account. IHC expression of HER2/neu was scored as: no staining or in $<10 \%$ of the tumor cells (score 0); faint/barely perceptible partial staining in $>10 \%$ of tumor cells (score $1+$ ); weak to moderate staining of the entire membrane and/or cytoplasma in $>10 \%$ of tumor cells (score $2+$ ) and strong staining in $>10 \%$ of tumor cells (score $3+$ ). Scores 0 and $1+$ were considered to be negative, and scores $2+$ and $3+$ positive for HER2/neu overexpression.

PCR and DNA sequencing. HER2 mutations in exons 18-23 encoding the kinase domain were detected. Genomic DNA from each of the tumor and normal cells was amplified with
Table I. Overexpression of HER2 and clinical parameters.

\begin{tabular}{lcc}
\hline & $\mathrm{n}$ & HER2(+) \\
\hline GC and non-tumor tissue & & \\
GC & 72 & $13(18.1 \%)$ \\
Non-tumor & 72 & $4(5.6 \%)$ \\
P-value & & 0.038 \\
Lauren classification & & \\
$\quad$ Intestinal type & 37 & $11(29.7 \%)$ \\
Diffuse type & 35 & $2(5.7 \%)$ \\
P-value & & 0.019 \\
TNM stage & & \\
I-II & 33 & $2(6.6 \%)$ \\
III-IV & 39 & $11(28.2 \%)$ \\
P-value & & 0.033 \\
\hline
\end{tabular}

GC, gastric cancer; TNM, tumor node metastasis.

three primer pairs covering exon 18-23. The primer sequences were (forward and reverse, respectively): exons 18-19 (5-GACACCTAGCGGAGCGATGC-3 and 5-ATGGGGTC CTTCCTGTCCTC-3), exons 20-21 (5-GTGATGGTTGGGA GGCTGTG-3 and 5-CTGCTCCTTGGTCCTTCAC-3), exons 22-23 (5-GGCCACCTCCCCACAACACA-3 and 5-GCTCAG CCACGCACATTTGAC-3). Calculations of cDNA of HER2 were carried out with respect to the ATG start codon (NM_004448).

The PCR reaction mixture was denatured for $1 \mathrm{~min}$ at $94^{\circ} \mathrm{C}$ and incubated for 35 cycles (denaturing for $60 \mathrm{sec}$ at $94^{\circ} \mathrm{C}$, annealing for $50 \mathrm{sec}$ at $58-59^{\circ} \mathrm{C}$ and extension for $50 \mathrm{sec}$ at $72^{\circ} \mathrm{C}$ ). Nest-PCR was performed when the amplification was not adequate for direct sequencing. The primers designed for the nest-PCR are not listed.

When the qualified PCR products were obtained, their direct sequencing was carried out using a cyclic sequencing kit (Perkin-Elmer, Foster City, CA, USA) according to the manufacturer's recommendation. When mutations were identified, further confirmation using sequencing in both directions was carried out.

Statistical analysis. The SPSS software package (SPSS, Inc., Chicago, IL, USA) was used in the statistical analysis. Comparison of the frequencies between the HER2/neu expression status and clinicopathological variables was performed with Fisher's exact test (two-sided) by SPSS version 12.0. The log-rank test was used for survival analysis. The Kaplan-Meier method was used to calculate survival curves. Multivariate analysis was carried out using Cox's proportional hazards model in order to identify the primary prognostic indicators that were independently associated with survival. A probability of 0.05 was considered to be a statistically significant difference.

\section{Results}

Overexpression and location of HER2/neu. Overexpression for HER2/neu using IHC staining was detected in 13 of the 72 


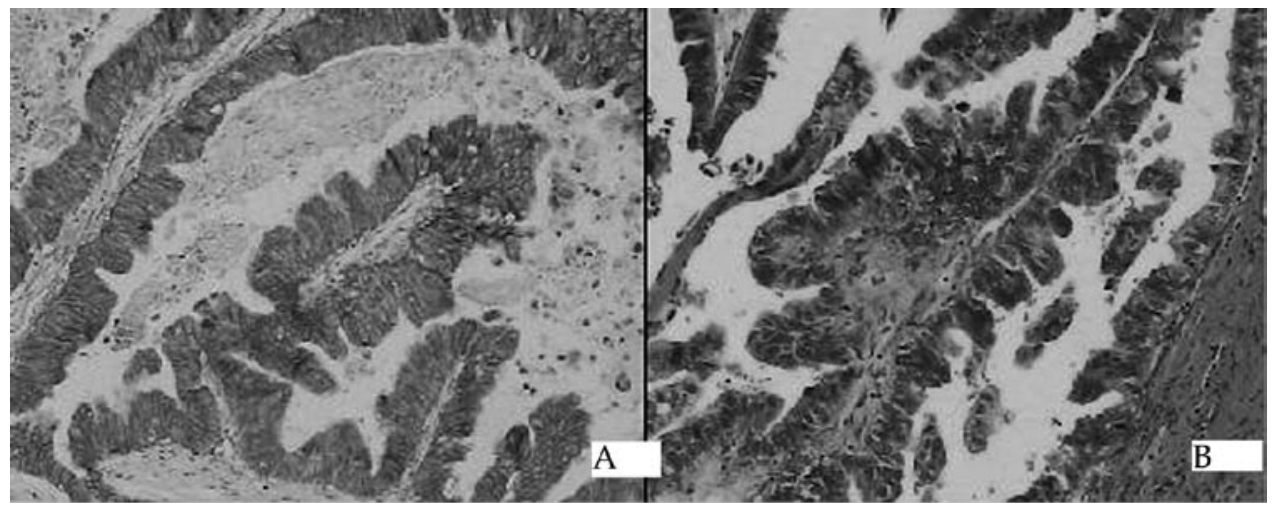

Figure 1. (A) HER2/neu immunohistochemistry and (B) counterparts with H\&E staining (x200). (A) Overexpression of HER2/neu in intestinal gastric cancer (membrane staining). Score $3+$.

Table II. Clinicopathological parameters and patient survival (log-rank test).

\begin{tabular}{lccc}
\hline & $\mathrm{n}$ & 1-year survival (\%) & P-value \\
\hline $\begin{array}{l}\text { Age (years) } \\
<60\end{array}$ & 34 & 61.3 & $<0.05$ \\
$\geq 60$ & 38 & 54.6 & \\
Gender & & & $>0.05$ \\
$\quad$ Male & 40 & 61.7 & \\
$\quad$ Female & 32 & 64.5 & \\
$\quad$ Lauren classification & & & $>0.05$ \\
$\quad$ Intestinal type & 40 & 60.2 & \\
$\quad$ Diffuse type & 32 & 57.2 & \\
TNM stage & & & $<0.01$ \\
$\quad$ I-II & 33 & 70.2 & \\
$\quad$ III-IV & 39 & 53.6 & \\
HER2 overexpression & & & \\
$\quad$ Absent & 59 & 71.2 & \\
Present & 13 & 59.7 & \\
\hline
\end{tabular}

GC patients and in 4 of the 72 tissue samples in the non-tumor group. A significant difference for HER2/neu overexpression between the GC and non-tumor group was observed (18.1 vs. $5.6 \%, \mathrm{P}<0.05$ ) (Table I). The location of HER2/neu protein was limited to the membrane (Fig. 1). No detectable immunoreactivity was noted in the negative control (data not shown), indicating the specificity of IHC staining.

As shown in Table I, HER2/neu overexpression was detected in 11 of the 37 intestinal-type and in 2 of the 35 diffuse-type GC cases. The rate of HER2/neu overexpression was higher in the intestinal-type GCs than that of the diffusetype (29.7 vs. $5.7 \%, \mathrm{P}<0.05)$.

Relationship between HER2/neu overexpression and clinicopathological parameters. No significant difference was noted in gender, age, tumor location and tumor size with respect to the overexpression of HER2/neu (data not shown). Table I shows that 11 of the 39 stage III-IV cases were HER2-positive, with a higher rate than that of stage I-II $(28.2$ vs. $6.6 \%, \mathrm{P}<0.05)$.

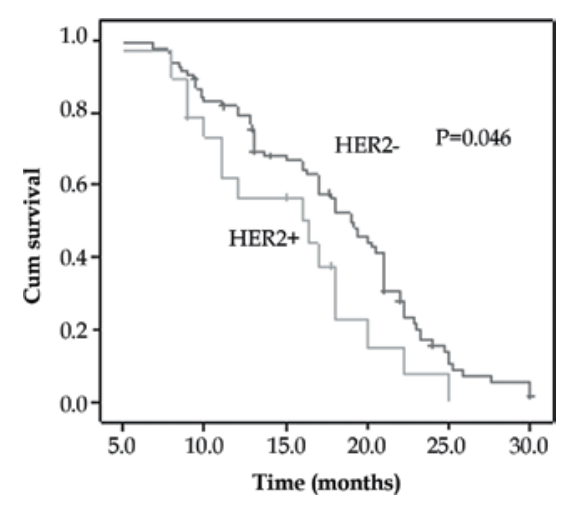

Figure 2. Kaplan-Meier curve for the overall survival of patients with overexpression of HER2/neu.

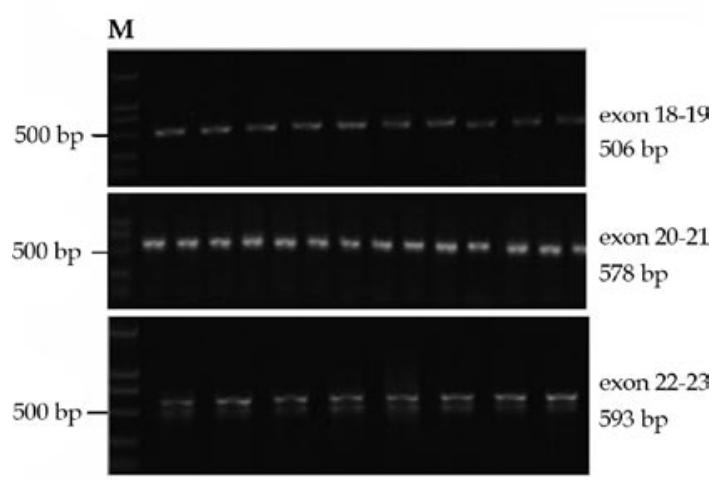

Figure 3. Qualified PCR products of HER2 exons 18-23.

Table III. Multivariate analysis (Cox's proportional hazards model).

\begin{tabular}{lcc}
\hline & HR $(95 \%$ CI $)$ & P-value \\
\hline Age & $1.961(1.386-2.446)$ & 0.047 \\
Diffuse vs. intestinal type & $1.332(0.974-2.543)$ & 0.615 \\
TNM stage I-II vs. III-IV & $4.322(3.116-11.024)$ & 0.000 \\
HER2 & $2.213(0.992-3.217)$ & 0.040 \\
\hline
\end{tabular}

HR, hazard ratio; CI, confidence interval. 
HER2/neu overexpression and survival. Univariate analysis (log-rank test) showed that age ( $\geq 60$ years), advanced TNM stage (III-IV) and the overexpression of HER2/neu correlated with a less favorable patient survival (Table II). Survival curves computed according to the Kaplan-Meier method (Fig. 2) showed that overexpression of HER $2 /$ neu correlated significantly with a decreased patient survival $(\mathrm{P}=0.046)$. Although the TNM stage was the most dominant prognostic factor, Cox's proportional hazard model also identified HER2/neu overexpression as an independent prognostic factor (Table III).

Detection of somatic mutations of HER2. Each case in our study exhibited qualified DNA bands comprising the kinase domain of HER2 for direct DNA sequencing (Fig. 3). In the 72 cases examined, no mutations were identified in the tumor or corresponding tissues.

\section{Discussion}

HER2/neu functionally belongs to the tyrosine kinase family. In carcinomas, HER2 acts as an oncogene, modulating the proliferation, invasion and apoptosis of tumor cells. Overexpression of HER2 protein in GC was first described in 1986 using IHC (16). The overexpression rates in GC were reported to be $9-38 \%$, and the staining location of HER2/ neu was found to be mainly in the cell membrane (17). The concordance between HER2/neu protein overexpression and gene amplification was recently elucidated in tumorigenesis, especially in the subgroup of cancers that scored $3+$ by IHC (18). The present study showed a positive HER2/neu overexpression in $18.1 \%$ of the GC patients and that the location of HER2/neu was largely membranous, consistent with previously reported observations.

Intestinal and diffuse types of GC differ in their epidemiology, pathogenesis, clinical outcome and genetic profiles (19). A high correlation between HER2/neu expression and the intestinal histologic type of GC was reported by several investigators. Lordick et al reported that HER2/neu positivity differed significantly according to the histological subtype (intestinal 34\% vs. diffuse 6\%) (20). A similar distribution of HER2/neu in the two histological types was also reported in another study involving Chinese GC patients (25.4 vs. $4.7 \%$, $\mathrm{P}<0.01)(21)$. Our results coincided with the above-reported data $(29.7$ vs. $5.7 \%, \mathrm{P}<0.05)$. However, the reasons for the selective overexpression of HER2/neu in the intestinal histological type remain complex and unclear.

The role of HER2/neu overexpression as a prognostic factor in gastric cancer remains controversial $(22,23)$. However, increased evidence suggests a direct correlation between HER2/neu overexpression and less favorable patient survival (24). In a series of 260 gastric cancers, Okegawa et al demonstrated that HER2/neu overexpression was an independent factor and correlated with serosal invasion and lymph node metastases (25). Our results demonstrated that HER2/ neu overexpression was statistically higher in stage III-IV than in stage I-II cases $(\mathrm{P}<0.05)$ and was closely associated with a less favorable patient outcome $(\mathrm{P}=0.046)$.

HER 2 is encoded by a gene located on chromosome 17q21 (16), and its kinase domain comprises 6 exons (exons 18-23). The discovery of somatic mutations in the tyrosine kinase domain of the EGFR in non-small cell lung cancer and their correlation with response to EGFR inhibitors has raised concerns about the detection of mutations of other HER genes, including HER2 and HER4 (26). Somatic mutations of the HER 2 gene have also been reported in gastric cancer, lung adenocarcinomas and other types of human cancer. It has been reported that the incidence of HER2 mutations in cancer tissues is low (2.9-5\%) (15). Of the total 6 exons of the HER2 gene, the majority of identified mutations are predominantly located in exons 19 and 20. Additionally, L755 and V777 appear to be the most easily affected sites and target the identical corresponding region as do EGFR insertions (15). Over 20 types of HER2 kinase domain mutations, including insertion/duplication and missense mutations, have been identified thus far (27,28). However, the functional impact of the mutated HER 2 gene in tumorigenesis remains unknown.

The incidence of genetic alterations in certain genes varies depending on ethnicity (13). Shigematsu et al investigated 394 adenocarcinoma cases and demonstrated that HER 2 mutations preferentially targeted individuals of Oriental ethnicity (3.9\%) compared to other ethnicities (0.7\%) (28). Since data are limited regarding HER2 mutations in Chinese GC patients, we investigated the presence of HER2 kinase domain mutations in 72 Chinese gastric carcinomas, and no mutations were identified. Although the number of GC patients enrolled in the present study was small, our results suggest that in Chinese GC patients, the incidence of somatic mutations in the HER2 kinase domain is anticipated to be a low-frequency rather than a high-frequency event.

\section{References}

1. Ahmed KM, Cao N and Li JJ: HER-2 and NF-kappaB as the targets for therapy-resistant breast cancer. Anticancer Res 26: 4235-4243, 2006.

2. Jin Q and Esteva FJ: Cross-talk between the ErbB/HER family and the type I insulin-like growth factor receptor signaling pathway in breast cancer. J Mammary Gland Biol Neoplasia 13: 485-498, 2008.

3. Derin D, Eralp Y, Ozluk Y, Yavuz E, Guney N, Saip P, Igci A, Ozmen V, Kücücük S, Aslay I, Aydiner A and Topuz E: Lower level of MAPK expression is associated with anthracycline resistance and decreased survival in patients with hormone receptor negative breast cancer. Cancer Invest 26: 671-679, 2008.

4. Burris $\mathrm{H}$ and Rocha-Lima C: New therapeutic directions for advanced pancreatic cancer: targeting the epidermal growth factor and vascular endothelial growth factor pathways. Oncologist 13: 289-298, 2008.

5. Duneau JP, Vegh AP and Sturgis JN: A dimerization hierarchy in the transmembrane domains of the HER receptor family. Biochemistry 46: 2010-2019, 2007.

6. Zaczek A, Brandt B and Bielawski KP: The diverse signaling network of EGFR, HER2, HER3 and HER4 tyrosine kinase receptors and the consequences for therapeutic approaches. Histol Histopathol 20: 1005-1015, 2005.

7. Yokoyama H, Ikehara Y, Kodera Y, Ikehara S, Yatabe Y, Mochizuki Y, Koike M, Fujiwara M, Nakao A, Tatematsu M and Nakanishi $\mathrm{H}$ : Molecular basis for sensitivity and acquired resistance to gefitinib in HER2-overexpressing human gastric cancer cell lines derived from liver metastasis. Br J Cancer 95: 1504-1513, 2006.

8. Pratilas CA, Hanrahan AJ, Halilovic E, et al: Genetic predictors of MEK dependence in non-small cell lung cancer. Cancer Res 68: 9375-9383, 2008.

9. De Graeff P, Crijns AP, ten Hoor KA, Klip HG, Hollema H, Oien K, Bartlett JM, Wisman GB, de Bock GH, de Vries EG, de Jong S and van der Zee AG: The ErbB signalling pathway: protein expression and prognostic value in epithelial ovarian cancer. Br J Cancer 99: 341-349, 2008. 
10. Kim KK, Lee JJ, Yang Y and Lee JH: Macrophage inhibitory cytokine-1 activates AKT and ERK-1/2 via the transactivation of ErbB2 in human breast and gastric cancer cells. Carcinogenesis 29: 704-712, 2008

11. Kim SY, Kim HP, Kim YJ, Oh do Y, Im SA, Lee D, Jong HS, Kim TY and Bang YJ: Trastuzumab inhibits the growth of human gastric cancer cell lines with HER2 amplification synergistically with cisplatin. Int J Oncol 32: 89-95, 2008.

12. Inui T, Asakawa A, Morita Y, Mizuno S, Natori T, Kawaguchi A, Murakami M, Hishikawa Y and Inui A: HER-2 overexpression and targeted treatment by trastuzumab in a very old patient with gastric cancer. J Intern Med 260: 484-487, 2006.

13. Paez JG, Jänne PA, Lee JC, Tracy S, Greulich H, Gabriel S, Herman P, Kaye FJ, Lindeman N, Boggon TJ, Naoki K, Sasaki H, Fujii Y, Eck MJ, Sellers WR, Johnson BE and Meyerson M: EGFR mutations in lung cancer: correlation with clinical response to gefitinib therapy. Science 304: 1497-1500, 2004.

14. Lynch TJ, Bell DW, Sordella R, Gurubhagavatula S, Okimoto RA, Brannigan BW, Harris PL, Haserlat SM, Supko JG, Haluska FG, Louis DN, Christiani DC, Settleman J and Haber DA: Activating mutations in the epidermal growth factor receptor underlying responsiveness of non-small cell lung cancer to gefitinib. $N$ Engl J Med 350: 2129-2139, 2004

15. Lee JW, Soung YH, Seo SH, Kim SY, Park CH, Wang YP, Park K, Nam SW, Park WS, Kim SH, Lee JY, Yoo NJ and Lee SH: Somatic mutations of ERBB2 kinase domain in gastric, colorectal and breast carcinomas. Clin Cancer Res 12: 57-61, 2006.

16. Akiyama $\mathrm{T}$, Sudo $\mathrm{C}$ and Ogawara $\mathrm{H}$ : The product of the human c-erbB-2 gene: a 185-kilodalton glycoprotein with tyrosine kinase activity. Science 232: 1644-1646, 1986.

17. Tokunaga A, Onda M, Okuda T, Teramoto T, Fujita I, Mizutani T, Kiyama T, Yoshiyuki T, Nishi K and Matsukura N: Clinical significance of epidermal growth factor (EGF), EGF receptor and c-erbB-2 in human gastric cancer. Cancer 75: 1418-1425, 1995.

18. Yano T, Doi T, Ohtsu A, Boku N, Hashizume K, Nakanishi M and Ochiai A: Comparison of HER2 gene amplification assessed by fluorescence in situ hybridization and HER2 protein expression assessed by immunohistochemistry in gastric cancer. Oncol Rep 15: 65-71, 2006.
19. Bulanov D: Gastric cancer - current state of the problem. Part I. Epidemiology. Pathology. Classification. Staging. Khirurgiia (Sofia) 4: 48-59, 2007

20. Lordick F, Bang YJ and Kang YK: HER2-positive advanced gastric cancer: similar HER2-positivity levels to breast cancer. Eur J Cancer 5: 271, 2007.

21. Cooperative Study Group of HER2 in China. Multicenter study on HER-2/neu gene amplification and protein expression in patients with gastric cancer. Chin J Dig 26: 657-660, 2006.

22. Tateishi M, Toda T, Minamisono $Y$ and Nagasaki $S$ : Clinicopathological significance of c-erbB-2 protein expression in human gastric carcinoma. Surg Oncol 49: 209-212, 1992.

23. Sasano H, Date F, Imatani A, Asaki S and Nagura H: Double immunostaining for c-erbB-2 and p53 in human stomach cancer cells. Hum Pathol 24: 584-589, 1993.

24. Chia S, Norris B, Speers C, Cheang M, Gilks B, Gown AM, Huntsman D, Olivotto IA, Nielsen TO and Gelmon K: Human epidermal growth factor receptor 2 overexpression as a prognostic factor in a large tissue microarray series of node-negative breast cancers. J Clin Oncol 26: 5697-5704, 2008.

25. Okegawa T, Kinjo $M$, Nutahara $K$ and Higashihara $E$ : Pretreatment serum level of HER2/nue as a prognostic factor in metastatic prostate cancer patients about to undergo endocrine therapy. Int J Urol 13: 1197-1201, 2006.

26. Soung YH, Lee JW, Kim SY, Wang YP, Jo KH, Moon SW, Park WS, Nam SW, Lee JY, Yoo NJ and Lee SH: Somatic mutations of the ERBB4 kinase domain in human cancers. Int J Cancer 118: 1426-1429, 2006.

27. Stephens $P$, Hunter $C$, Bignell G, et al: Lung cancer: intragenic ERBB2 kinase mutations in tumors. Nature 431: 525-526, 2004.

28. Shigematsu H, Takahashi T, Nomura M, Majmudar $K$, Suzuki M, Lee H, Wistuba II, Fong KM, Toyooka S, Shimizu N, Fujisawa T, Minna JD and Gazdar AF: Somatic mutations of the HER2 kinase domain in lung adenocarcinomas. Cancer Res 65: 1642-1626, 2005 